\title{
Exercise and menstrual function: A review study
}

\author{
Sikiru Lamina ${ }^{1 *}$, Charles Ikechukwu Ezema ${ }^{1}$, Uche A. Ezugwu $^{2}$, Augustine A. Amaeze $^{2}$, \\ Maduabuchukwu Joseph Nwankwo ${ }^{3}$, Amaeze Florence Ngozi $^{4}$ \\ ${ }^{1}$ Department of Medical Rehabilitation, Faculty of Health Sciences and Technology, University of Nigeria, Enugu Campus, Enugu, \\ Nigeria; *Corresponding Author: siklam_86@yahoo.co.uk \\ ${ }^{2}$ Physiotherapy Department, University of Nigeria Teaching Hospital, Ituku Ozalla, Nigeria \\ ${ }^{3}$ Department of Medical Rehabilitation, Faculty of Health Sciences and Technology, Nnamdi Azikiwe University, Awka, Nigeria \\ ${ }^{4}$ Nursing Department, University of Nigeria Teaching Hospital, Ituku Ozalla, Nigeria
}

Received 17 September 2013; revised 19 October 2013; accepted 1 November 2013

Copyright (C) 2013 Sikiru Lamina et al. This is an open access article distributed under the Creative Commons Attribution License, which permits unrestricted use, distribution, and reproduction in any medium, provided the original work is properly cited.

\begin{abstract}
At present there is no conclusive evidence that participation in exercise affects menstruation and is equivocal and unclear whether menstrualtion affects athletic performance. An attempt has therefore been made in this paper to discuss the effects of menstruation on exercise performance and vice versa. The paper reviewed that women experiencing pre-menstrual syndrome will not likely perform well and that menstrual irregularity is much higher in athletes than sedentary women. The paper also reviewed that athletes reach menarche later than sedentary sisters. The review concluded that competing women experiencing premenstrual syndrome might get control over their menstruation through medically recommended low dose oral contraceptive. The paper recommended that athletes experiencing menstrual irregularities and disturbances should seek medical consultation and management before further training.
\end{abstract}

Keywords: Exercise; Menstruation; Female; Athletes

\section{INTRODUCTION}

The normal menstrual cycle is 28 days, although normal cycles vary between 22 and 36 days. The menstrual cycle consists of follicular and luteal phases. The follicular phase (menstrual \& proliferative phases) begins on the first day of menstruation and ends with ovulation. The luteal phase begins at ovulation and ends with menstruation. The luteal phase lasts 10 - 16 days. In a given woman, luteal phase length is very consistent; the follicular phase is much more variable [1-3].
Many factors (body composition, poor nutrition, exercise, pregnancy, reproductive immaturity, psychological stress, acute and chronic endocrine alteration) can disrupt the menstrual cycle and identifying a single cause has been very difficult $[4,5]$. The present state of knowledge makes it difficult to determine accurately if exercise or a combination of other factors could alter menstrual function [6].

At present there is no conclusive evidence that participation in exercise or sporting events during menstruation is harmful. In addition, it is unclear whether menstruation per se and the discomfort associated with primary dysmenorrhea affect performance [7]. Regular, asymptomatic menstruation is usually considered a measure of general good health in females after a regular rhythm has been established. Conversely, medical authorities had felt that any deviation from this normal rhythmic pattern may be the first indication of over training. The purpose of the present study was to review the relationship between exercise and menstrual function.

\section{EFFECTS OF MENSTRUATION ON ATHLETES' PERFORMANCE}

Although, there is no consensus report on the effect of menstruation on athlete performance [7]. Surveys of athletes have indicated a diversity of opinion regarding the effect of menstruation on athletic performance used, 37\% to $73 \%$ believing that performance is not affected, $13 \%$ to $29 \%$ indicating improved performance, particularly during menstruation [8].

Alterations in athletic performance experienced during different phases of the menstrual cycle are subject to considerable individual variability. Some women have absolutely no noticeable change in their performance ability at any time during their menstrual cycle, yet others have considerable difficulty in either the pre-flow or the 
early flow phases or during both. The number of women who reported impaired performance during the flow phase is approximately the same as those who experienced no difficulty. In fact, some female athletes have repeatedly set world records during the flow phase. Adding to the confusion, much of the information available is based on subjective statement made by athletes during informal surveys [3].

Several studies [9-12], Brutsaert et al. [13] and Redman et al. [14] have suggested that athletic performance is affected by menstrual cycle phases. Several others [15-17] have also reported a contrary notion. The disagreement between these studies could be due to the small number of subjects tested to large individual variations or to inadequately control experimental designs. Dysmenorrhea, in practical terms affects athletic performance more than amenorrhea. Many female athletes suffer from dysmenorrhea. Dysmenorhea distracts from the feeling of well-being. For that reason, it negatively affects performance; some of the problem may be psychological induced [6].

The risk of athletic injury is higher in women with Pre Menstrual Syndrome (PMS). The most important symptoms associated with athletic injuries are irritability, breast swelling and abdominal congestion. Any woman who experiences PMS or dysmenorrhea will likely not perform as well while she is experiencing symptoms. For these women, some degree of control over their menstrual cycle is possible through the use of low dose oral contraceptives [3].

\section{EFFECTS OF EXERCISE OR SPORTING EVENTS ON MENSTRUATION}

The risks to sportswomen of exercise related menstrual dysfunction and impaired bone health are important and under-recognised. Exercise related menstrual dysfunction may include any abnormality along the continuum of luteal phase deficiency, annovulation, oligomenorrhoea, amenorrhoea, and delayed menarche. Such dysfunction is multifactorial in origin, with a high degree of individual variation, but its main underlying mechanism is hypothalamic inhibition with suppression of gonadotrophin releasing hormone pulsatility (the frequency at which pulses of the hormone are released by the hypothalamus) [4].

When menstrual dysfunction (in particular amenorrhoea) occurs in sportswomen in combination with low bone mass and energy deficit, the syndrome is termed the "female athletic triad." This is a complex and poorly understood disorder seen in females who exercise intensively [5,18]. Thompson [19] described female Athlete Triad is a life-threatening syndrome defined by disordered eating, amenorrhea, and osteoporosis. Athletes in lightweight sports (distance running, gymnastics, lightweight rowing) are at high risk, although the syndrome can arise in relation to any sport. The energy deficit is usually related to eating disorders and is partly influenced by peer pressure. Genetic, neurochemical, and psychodevelopmental factors may also contribute, along with the physical and psychological effects of training and competition. The long term effects tend to be greatest in young athletes who start intense exercise before menarche. These athletes have an increased chance of delayed menarche, impairment of growth and pubertal progression, subsequent menstrual dysfunction, and suboptimal bone health $[4,20]$.

The incidence of menstrual irregularity is much higher in athletes than in sedentary women. Secondary amenorrhea in athletes is as high as $44 \%$. The incident in general population is only $2 \%-5 \%[4,20]$. Many authorities [6, 21] have reported that high training volume and increased intensity increase the incidence of amenorrhea. Women involved in strength sport, such as body building or weight lifting, have an increased incidence of amenorrhea, although the increase is lower than in endurance athletes. Brooks et al. [6] also stated that women who have been pregnant before becoming involved in exercise training have a much lower incidence of amenorrhea than women who have not and those women with previous menstrual irregularity are much more likely to have amenorrhea with training.

Willmore and Costill [3] reported that the prevalence of secondary amenorrhea and oligomenorrhea among athletes is not well documented, but is estimated to vary from approximately 5\% to $40 \%$ or higher, depending on the sport or activity and the level of competition. This is considerably higher than the estimated $2 \%$ to $3 \%$ prevalence for amenorrhea and $10 \%$ to $12 \%$ prevalence for oligomenorrhea in the general population. Athletes who present with amenorrhoea are at the severe end of the spectrum of exercise related menstrual dysfunction. Subtle menstrual disturbances are more common, occurring in nearly four fifths of very active women [12]. The impact of this on bone mineral density is unclear [12], and there is no evidence that women whose menstrual function recovers develop chronic infertility [22].

Giannini, Melemis, Martin \& Folts [23] found that PMS may be related to altered B-endorphin metabolism in the central nervous system (CNS). Increased activity or norepinephrine may also be important. PMS symptoms such as backache, headache, cramps and emotional distress may improve with exercise. Exercise may be beneficial because it increases B-endophines in the central nervous system (CNS).

Exercise associated with amenorrhea may also increase the risk of coronary heart diseases. Oestrogen increase the blood levels of high density lipoproteins and apoprotein A-1 (thought to provide some protection 
against coronary heart disease) and decrease low-density lipoprotein. Intense training, leading to oestrogen suppression and amenorrhea, may decrease the protective effects of oestrogen. No specific threshold at which exercise leads to menstrual dysfunction has been defined because contributing physiological and psychological factors produce considerable individual variation [6].

Menarche: Sexual maturation in females is marked by menarche, the first menstruation. Menarche typically occurs after the peak of the adolescent growth spurt, it may occur when enough gonadotropin hormones are released from the pituitary and hypothalamus. It may occur at approximately 12.9 years and that athletes, particularly in sport such as gymnastics, swimming and running, reach menarche later than non-athletes. It has been reported that menarche occurred later in swimmers than in their sedentary sisters. This suggests that delayed menarche is influenced by genetics as well as training $[3,6]$. There also exist ethnic differences in the onset of menarche. However, the influence of diet on the onset of menarche is unknown $[6,21]$. The consequences of delayed menarche in athletes are not known.

Menopause: A reviewed study on the effect of exercise training programme on post-menopausal women by Snow-Heart and Marcus [24] showed that results in the last two decades, has been contradictory and inconclusive. This may be attributed to potential confounders such as oestrogen status, calcium consumption, duration and intensity of the exercise programme which were not controlled. More studies are still needed to further evaluate the effects of exercise training on menopause and vice-versa. Sedentary women are more likely to have moderate to severe hot flushes compared to women who exercise [25]. Hot flush is the sensation of warmth spreading from the trunk to the face and is common after ovarian function has ceased (menopause).

\section{MANAGEMENT OF MENSTRUAL DYSFUNCTION}

Screening may be useful in women who exercise vigorously. Dietary, medical, and training histories should be taken from any apparently physically fit woman presenting with recurrent or resistant injuries to soft tissue or bone (in particular stress fractures). Urinalysis to detect ketonuria will suggest inadequate caloric intake, and thyroid function tests (yielding normal or raised thyroid stimulating hormone and reduced free thyroxine) will indicate a hypometabolic state in those with feeding disorder [22].

Women who are amenorrhoeic will need the standard investigations. In women with suspected luteal phase deficiency basal body temperature should be monitored, surges in luteinising hormone measured with ovulation predictor kits, multiple samplings of serum progesterone taken, and ideally, endometrial biopsy carried out. Women with suspected bone loss may need a DEXA (dual energy X ray absorptiometry) scan, preferably including peripheral sites such as the tibia and forearm [26].

Management of exercise related menstrual dysfunction aims primarily to restore normal menstrual cycles. Education of athletes, coaches, peers, and managers and parents about the risks of excessive exercise in girls and women is of paramount importance. Dietary counseling to ensure a positive energy balance and adequate calcium and vitamin $\mathrm{D}$ intake $[27,28]$ and advice on altering the volume and intensity of training programmes and reducing the stressors of competition, may be effective [4]. Supplementation with combined oestrogen and progesterone should help maintain bone mass, although it will not rebuild what has already been lost [29]. Treatment with recombinant leptin may have a role in the future but evidence is preliminary [30].

\section{CONCLUSION}

Conclusively, the effect of menstruation on performance is equivocal and unclear, but a woman who is experiencing PMS will likely not perform well while she is experiencing the symptoms. For these women some degree of control over their menstrual cycle is possible through the use of medically prescribed low dose oral contraceptive. Also, the incident of menstrual irregularities is much higher in athletes than in sedentary counterparts; this is as a result of the decrease in GonadotropinReleasing Hormone (GnHR) and Luteinizing Hormone (LH) that leads to reduction in the level of oestrogen that disrupts the menstrual cycle in athletes.

\section{RECOMMENDATION}

Based on the findings of the present review the following are hereby recommended:

1) Well controlled studies to further evaluate the effects of menstruation on performance and vice-versa, particularly in African population.

2) Female athlete experiencing menstrual irregularities and disturbances should undergo a detailed medical investigation and management before further training.

3) Extensive studies to further evaluate the effect of delayed menarche on athletes' reproductive health are needed.

\section{REFERENCES}

[1] Barretti, K.E., Barman, S.E., Boitano, S. and Brooks, H. (2009) Ganong's review of medical physiology. 24th Edition, Lange Medical Book, Connecticut.

[2] Horton, T.J., Miller, E.K., Glueck, D. and Tench, K. (2002) No effect of menstrual cycle phase on glucose kinetics and fuel oxidation during moderate-intensity exer- 
cise. American Journal of Physiology-Endocrinology and Metabolism, 282, E752-E762.

[3] Wilmore, J.H. and Costill, D.L. (1994) Physiology of sport and exercise. Human Kinetics, Champaign.

[4] DeCree, C. (1998) Sex steroid metabolism and menstrual irregularities in the exercising female. A review. Sports Me, 25, 369-406. http://dx.doi.org/10.2165/00007256-199825060-00003

[5] Otis, C.L., Drinkwater, B., Johnson, M., Loucks, A. and Wilmore, J. (1997) American College of Sports Medicine position stand. The female athlete triad. Medicine and Science in Sports and Exercise, 29, i-ix. http://dx.doi.org/10.1097/00005768-199705000-00037

[6] Brooks, C.A., Fahey, T.D., White, T.P. and Baldwin, K.M. (2005) Exercise physiology: Human bioenergetics and its application. 4th Edition, Mayfield Publishing Company, Mountain View.

[7] Carlberg, K., Peake, G.T. and Buckman, M.T. (1988) Exercise and the menstrual cycle. In: Appenzeller, O. (Ed.), Sports Medicine, Urban \& Schwarzenberg, Baltmore, 161-180.

[8] Lebrun, C.M. (1994) The effect of the phase of the menstrual cycle and the birth control pill on athletic performance. Clinical Journal of Sport Medicine, 13, 419-441.

[9] Bailey, S.P., Zacher, C.M. and Mittleman, K.D. (2000) Effect of menstrual cycle phase on carbohydrate supplementation during prolonged exercise to fatigue. Journal of Applied Physiology, 88, 690-697.

[10] Beidleman, B.A., Rock, P.B., Muza, S.R., Fulco, C.S., Forte Jr., V.A. and Cymerman, A. (1999) Exercise E and physical performance at altitude are not affected by Menstrual cycle phase. Journal of Applied Physiology, 86, 1519-1526.

[11] McCracken, M., Ainsworth, B. and Hackney, A.C. (1994) Effects of the menstrual cycle phase on the blood lactate responses to exercise. European Journal of Applied Physiology, 69, 174-175. http://dx.doi.org/10.1007/BF00609412

[12] DeSouza, M.J. (2003) Menstrual disturbances in athletes: A focus on luteal phase defects. Medicine \& Science in Sports \& Exercise, 35, 1553-1563. http://dx.doi.org/10.1249/01.MSS.0000084530.31478.DF

[13] Brutsaert, T.D., Spielvogel, H., Caceres, E.D., Araoz, M., Robert, T., Chatterton, R.T. and Vitzthum, V.J. (2002) Effect of menstrual cycle phase on exercise performance of high-altitude native women at $3600 \mathrm{~m}$. The Journal of Experimental Biology, 205, 233-239.

[14] Redman, L.M. and Weatherby, R.P. (2004) Measuring performance during the menstrual cycle: A model using oral contraceptives. Medicine \& Science in Sports \& Exercise, 36, 130-136.

http://dx.doi.org/10.1249/01.MSS.0000106181.52102.99

[15] Moore, L.G. (1997) Women at altitude: Overview. In: Houston, C.S. and Coates, G. (Eds.), Hypoxia, Queen City Printer, Burlington, 1-7.

[16] Edwards, N., Wilcox, I., Polo, O.J. and Sullivan, C.E. (1996) Hypercapnic blood pressure response is greater during the luteal phase of the menstrual cycle. Journal of
Applied Physiology, 81, 2142-2146.

[17] Regensteiner, J.G., McCullough, R.G., McCullough, R.E., Pickett, C.K. and Moore, L.G. (1990) Combined effects of female hormones and exercise on hypoxic ventilatory response. Respiratory Physiology, 82, 107-114. http://dx.doi.org/10.1016/0034-5687(90)90027-V

[18] Birch, K. (2005) Female athlete triad. ABC of sports and exercise medicine. British Medical Journal, 330, 244246. http://dx.doi.org/10.1136/bmj.330.7485.244

[19] Thompson, S.H. (2007) Characteristics of the female athlete triad in collegiate cross-country runners. Journal of American College Health, 56, 129-136. http://dx.doi.org/10.3200/JACH.56.2.129-136

[20] Locks, A.B. (1990) Effects of exercise training on the menstrual cycle. Exercise \& mechanisms. Medicine and Science in Sports and Exercise, 22, 275-280.

[21] Devris, H.A. and Housh, T.J. (1994) Physiology of exercise for physical education, athletic and exercise science. 5th Edition, NCB Brown and Benchmark Publishers, Madison.

[22] (2007) Exercise and menstrual function. British Medical Journal, 334, 164.

http://dx.doi.org/10.1136/bmj.39043.625498.80

[23] Giannini, A.J., Melemis, S.M., Martin, D.M. and Folts, D.J. (1994) Symptoms of premenstrual syndrome as a function of beta endorphin; two sub types. Prog. Neutropsych ophamacol. Psychiatry, 18, 321-327.

[24] Snow-Heart, C. and Marav, R. (1991) Exercise bone mineral density and osteoporosis. Exercise and Sport Sciences Reviews, 19, 361-388.

[25] Iversson, T., Spetz, A.C. and Hammer, M. (1998) Physical exercise and vasomotor symptoms in postmenopausal women. Mauritas, 29, 139-146. http://dx.doi.org/10.1016/S0378-5122(98)00004-8

[26] Slemenda, C.W. and Johnson, C.C. (1993) High intensity activities in young women: Site specific bone mass effects among female figure skaters. Bone and Mineral, 20, 125-132. http://dx.doi.org/10.1016/S0169-6009(08)80021-9

[27] Thompson, S.H. (2007) Characteristics of the female athlete triad in collegiate cross-country runners. Journal of American College Health, 56, 129-136. http://dx.doi.org/10.3200/JACH.56.2.129-136

[28] Dueck, C.A., Matt, K.S., Manore, M.M. and Skinner, J.S. (1996) Treatment of athletic amenorrhea with a diet and training intervention programme. International Journal of Sport Nutrition, 6, 24-40.

[29] Hergenroeder, A.C. (1995) Bone mineralization, hypothalamic amenorrhea, and sex steroid therapy in female adolescents and young adults. Journal of Pediatrics, 126, 683-692. http://dx.doi.org/10.1016/S0022-3476(95)70393-4

[30] Welt, C.K., Chan, J.L., Bullen, J., Murphy, R., Smith, P. and DePaoli, A.M. (2004) Recombinant human leptin in women with hypothalamic amenorrhea. New England Journal of Medicine, 351, 987-997. http://dx.doi.org/10.1056/NEJMoa040388 